\title{
Relacionamentos Amorosos e Homossexualidade: Revisão Integrativa da Literatura
}

\author{
Geysa Cristina Marcelino Nascimento \\ Fabio Scorsolini-Comin ${ }^{1}$ \\ Departamento de Psicologia, Universidade Federal do Triângulo Mineiro, \\ Uberaba, MG, Brasil \\ Anne Marie Germaine Victorine Fontaine \\ Faculdade de Psicologia e Ciências da Educação da Universidade do Porto, \\ Porto, Portugal \\ Manoel Antônio dos Santos \\ Departamento de Psicologia da Universidade de São Paulo, Ribeirão Preto, SP, Brasil
}

\begin{abstract}
Resumo
Este estudo teve por objetivo apresentar uma revisão integrativa da literatura científica nacional e internacional acerca dos relacionamentos amorosos entre pessoas do mesmo sexo. Foram consultadas as bases SciELO, LILACS, PePSIC, Oxford, Wilson, Ovid e EBSCO, de 2000 a 2013, e recuperados 20 artigos, sendo a maioria estudos teóricos. Predominaram estudos sobre o casamento e o exercício da parentalidade em casais homossexuais, além de referências às políticas públicas e aos aspectos culturais e históricos envolvidos. Destaca-se a necessidade de mais investigações empíricas com sujeitos com orientação homossexual, que permitam avançar em relação à tendência predominantemente teorizante do conhecimento produzido. Também devem ser priorizadas particularidades das relações homoafetivas em vez de sua comparação com arranjos heterossexuais, que termina por reforçar o pressuposto da heteronormatividade.
\end{abstract}

Palavras-chave: Homossexualidade, amor, intimidade, casamento, relações familiares.

\section{Loving Relationships and Homosexuality: Integrative Literature Review}

\begin{abstract}
This study had as an objective to present an integrative review of scientific national and international literature about same-sex relationships. The following databases were consulted: SciELO, LILACS, PePSIC, Oxford, Wilson, Ovid e EBSCO, 2000 to 2013, and 20 articles were retrieved, most of them theoretical studies. Studies about marriage and parenthood exerted by homosexual couples are predominant, and also references to public policies and cultural and historical aspects involved. The study highlights the need for more empirical research with homosexual characters, who will let us advance in relation to the predominantly theorizing tendency of produced knowledge. It must also be prioritized
\end{abstract}

Endereço para correspondência: Universidade Federal do Triângulo Mineiro, Departamento de Psicologia, Avenida Getúlio Guaritá, 159, $3^{\circ}$ andar, Abadia, Uberaba, MG, Brasil 38025440. E-mail: geysanascimento@ terra.com.br, fabioscorsolini@gmail.com, fontaine@fpce.up.pt e masantos@ffclrp.usp.br Agência de financiamento: Conselho Nacional de Desenvolvimento Científico e Tecnológico (CNPq). 
peculiarities of homoaffective relations rather than their comparison with heterosexual arrangements, which ends up reinforcing the assumption of heteronormativity.

Keywords: Homosexuality, love, intimacy, marriage, family relations.

\section{Las Relaciones Amorosas y la Homosexualidad: Una Revisión Integradora de la Literatura}

\section{Resumen}

Este estudio tiene como objetivo presentar una revisión integradora de la literatura científica nacional e internacional sobre las relaciones amorosas en las personas de mismo género. Fueron consultadas las bases SciELO, LILACS, PePSIC, Oxford, Wilson, EBSCO y Ovid, de 2000 a 2013, y fueron recuperados 20 artículos. Predominan estudios teóricos sobre el matrimonio y la paternidad ejercida por las parejas homosexuales, así como las referencias a las políticas públicas y los aspectos culturales e históricos involucrados. El estudio pone de relieve la necesidad de más investigación empírica con sujetos homosexuales, lo que permite avanzar contra la tendencia predominante teorización del saber. También deben ser priorizadas peculiaridades de las relaciones homosexuales en lugar de su comparación con los arreglos heterosexuales, lo que termina por reforzar la asunción de la heteronormatividad.

Palabras clave: Homosexualidad, amor, intimidad, matrimonio, relaciones familiares.

Durante séculos, a relação íntima entre duas pessoas do mesmo sexo foi vista, de acordo com a moral vigente, como pecado, perversão, desvio ou crime (Andrade \& Ferrari, 2009). As relações afetivas e as variantes do desejo sexual que se afastam da heteronormatividade, como a homossexualidade, a bissexualidade e a transexualidade, frequentemente se inscreveram no imaginário coletivo como evidências de desvio, doença, abjeção ou falha de caráter, atraindo sobre si representações desqualificadoras que reforçam preconceitos e promovem discriminação e intolerância (Galli, Vieira, Giami, \& Santos, 2013; Santos, Brochado, \& Moscheta, 2007).

Os casais homoafetivos têm atraído a atenção de estudos que buscam compreender a dinâmica conjugal estabelecida com base em movimentos de ruptura e permanência dos modelos consagrados pelos relacionamentos heterossexuais (Moscheta $\&$ Santos, 2006). Nessa vertente, os sentidos do relacionamento conjugal produzidos por esses casais podem ser vistos tanto na sua dimensão de revolução como de acomodação em relação à heteronorma (Moscheta \& Santos, 2009). Uma tendência que se delineia nesse campo de investigações dos casais homoafetivos é a de privilegiar enfoques metodológicos que fo- mentem contribuições que permitam a compreensão de suas experiências singulares.

$\mathrm{Na}$ contemporaneidade, assiste-se a uma maior pluralização nas formas de expressão das relações, tanto afetivas quanto de intimidade sexual. Tal movimento é proveniente da retroalimentação das mudanças culturais e históricas dos padrões que regulam as relações sociais (Lomando \& Wagner, 2009; Pereira, Torres, Pereira, \& Falcão, 2011; Prado \& Machado, 2008; Moscheta \& Santos, 2006; Richlin, 2005; Simões \& Facchini, 2009; Spencer, 1996; Uziel et al., 2006).

No bojo dessas mudanças, floresce uma crítica acirrada à visão binária do par "homo"/ "heterossexualidade", o que torna necessário ponderar criticamente sobre a escolha por uma categoria clínica (implícita no uso do termo "homossexual", por exemplo) em vez de uma categoria exclusivamente política ou cultural (Souza \& Carrieri, 2010). Nesse ponto, a categoria gênero pode ser entendida como uma construção social engendrada a partir do aparato biológico que nos identifica como machos ou fêmeas (Badinter, 1993; Guimarães, 2009). Já a identidade de gênero é compreendida com referência ao sentimento e à convicção íntima 
que se tem de pertencer a um sexo. Assim, as categorias "masculino" e "feminino" seriam construídas como polaridades, engendradas por uma visão dicotomizante que mascara as relações de poder (Santos, 2011; Souza \& Carrieri, 2010).

De acordo com o Censo do Instituto Brasileiro de Geografia e Estatística (IBGE, 2011), há cerca de 60 mil casais constituídos por pessoas do mesmo sexo no Brasil. Tal dado oficial dá visibilidade ao fenômeno da parceria homoafetiva e revela que as famílias homoparentais questionam os cientistas sociais acerca da estrutura de parentesco, interpelam os juristas sobre o que seria natural na filiação e interrogam os psicólogos sobre como é o desenvolvimento psicológico da criança que vive em famílias distintas daquelas que a sociedade considera como tradicional (Perroni \& Costa, 2008). Conforme destacado por Zambrano (2006), as famílias constituídas pelo casal parental do mesmo sexo são caracterizadas pela não cristalização de papéis de gênero, o que instaura a possibilidade de arranjos familiares que não são, necessariamente, organizados pelas polaridades "masculino" e "feminino" e pelas hierarquias de gênero.

A conjugalidade pode ser definida como o estabelecimento de união ou enlace entre duas pessoas, não sendo necessário que haja o estabelecimento de um contrato formal entre elas, bastando existir um laço de intimidade e afeto (Diehl, 2002; Moraes, Moraes, Veloso, Alves, \& Tróccoli, 2009; Scorsolini-Comin \& Santos, 2012). No esteio da psicanálise, Féres-Carneiro (1998) define a conjugalidade como um processo de construção de uma realidade comum, partilhada e permanentemente alterada por ambos os cônjuges. Na vertente sociológica de Heilborn (1995), a conjugalidade é entendida como um núcleo de trocas afetivo-sexuais caracterizado por uma não-demarcação rígida no que tange aos papéis conjugais. E na perspectiva de Vaitsman (1994), noções essencialistas consagradas, como identidade, casamento e família, estão passando por ampla revisão nas circunstâncias pós-modernas e gradualmente dão lugar a relações mais flexíveis e plurais. Em outra vertente, Mosmann, Lomando e Wagner (2010) também identificam a maior flexibilidade dos papéis de gênero e a centralidade assumida pelo amor na fundação do casamento contemporâneo. Agrupando esses diferentes posicionamentos teóricos, podemos dizer que, na definição de conjugalidade, devem coexistir tanto a expressão da autonomia individual quanto os movimentos de fusão, ou seja, há um movimento pendular entre ser dois e ser um ao mesmo tempo, o que se aplicaria a todos os relacionamentos amorosos, ou seja, em pares formados por pessoas do mesmo sexo ou não.

No entanto, ainda são escassos os estudos que elegem os denominados arranjos entre pessoas do mesmo sexo como relevantes para ampliar a compreensão científica acerca dos relacionamentos amorosos, ainda que observemos um sensível aumento nas publicações destinadas à temática, notadamente a partir dos anos 2000 (Pennings, 2011; Tavares, Souza, Ferreira, \& Bomtempo, 2010; Toledo, 2008; Vecho \& Schneider, 2005). As lacunas do conhecimento sistematizado nessa área acabam não potencializando o desenvolvimento da cidadania e da qualidade de vida da população LGBT (Lésbicas, Gays, Bissexuais, Travestis e Transexuais), condições necessárias garantir a atenção às suas necessidades, por exemplo, no cuidado oferecido em equipamentos de saúde (Santos et al., 2007). Feitas essas considerações, este estudo teve por objetivo realizar uma revisão integrativa da literatura científica nacional e internacional acerca dos relacionamentos amorosos estabelecidos entre pessoas do mesmo sexo.

\section{Método}

\section{Tipo de Estudo}

Trata-se de uma revisão integrativa da literatura científica. Esse tipo de estudo objetiva, por meio de uma metodologia sistemática de busca, seleção e análise, descrever a produção científica acerca de uma temática, destacando o estado da arte e apresentando as possibilidades de futuras investigações. Trata-se de empreender uma leitura crítica da literatura científica, na qual são identificados e selecionados estudos com rigor e método científico, com o propósito de 
analisá-los para que se possa delinear um perfil dos estudos publicados, contribuindo para a discussão acerca dos resultados de pesquisa e para o desenvolvimento de pesquisas futuras. A revisão integrativa é um tipo de revisão sistemática que comporta tanto uma dimensão de categorização, de caráter descritivo, como uma faceta de análise crítica, que aponta as tendências consolidadas, bem como as lacunas e necessidades de investigação ainda não suficientemente contempladas (Scorsolini-Comin, 2014). O problema investigado foi: "Como se configuram, segundo a literatura científica recente, os relacionamentos amorosos estabelecidos por pessoas do mesmo sexo?".

\section{Bases Indexadoras}

Este estudo envolveu uma busca sistemática nos seguintes indexadores eletrônicos: SciELO, LILACS, PePSIC, Oxford, Wilson, Ovid e EBSCO. Os descritores utilizados foram: "homossexualidade", "casamento" e "namoro", e seus correspondentes em inglês: homosexuality, marriage e courtship. Foram realizados os cruzamentos possibilitados pela combinação dos termos utilizados, a partir do operador booleano "and".

\section{Critérios de Inclusão}

Os critérios estabelecidos para a inclusão dos estudos foram: (a) artigos indexados; (b) redigidos nos idiomas português ou inglês; (c) publicados no período de janeiro de 2001 a dezembro de 2013; (d) com temática pertinente ao objetivo da revisão. A seleção apenas de artigos indexados visou a cotejar produções que passam, necessariamente, por um processo de avaliação por pares, com rigoroso controle de qualidade. A adoção desse critério baseou-se em outras revisões, com semelhante grau de rigor, que indicaram a necessidade de se tomar tal cuidado como balizador da condição de produção científica em dado período (Scorsolini-Comin, 2014). A seleção de artigos publicados entre 2001 e 2013 visou a abarcar apenas publicações recentes, a fim de traçar um retrato mais fiel da produção contemporânea, bem como apontar possíveis la- cunas e aberturas para novos estudos. Não foram feitas restrições em relação ao tipo de delineamento metodológico (estudos teóricos, empíricos, de revisão, estudos de caso ou outros), nem em relação às abordagens teóricas ou às áreas nas quais as pesquisas foram desenvolvidas.

\section{Critérios de Exclusão}

1. Livros, capítulos de livro, resenhas, cartas, notícias, resumos, anais de congressos, editorais, dissertações e teses;

2. Temática central distanciada do objetivo da revisão;

3. Artigos publicados no período anterior a 2001.

\section{Procedimento}

O levantamento bibliográfico ocorreu em abril de 2014. Em um primeiro momento, foi realizada uma leitura minuciosa dos resumos encontrados a partir dos unitermos utilizados e da combinação dos mesmos, excluindo-se os artigos que não se enquadravam nos critérios de inclusão elencados e contabilizando uma única vez os registros repetidos. Após uma primeira seleção realizada pelo exame dos resumos, os estudos selecionados foram recuperados, examinados e lidos na íntegra. Posteriormente, em função da maior ou menor proximidade com o tema de interesse, uma nova seleção foi realizada, restringindo-se a revisão apenas aos artigos diretamente relacionados aos relacionamentos amorosos entre pessoas do mesmo sexo. Foram incorporadas à revisão apenas as publicações recuperadas nessa última seleção, que constituíram o corpus de análise do presente estudo.

\section{Resultados e Discussão}

Foram selecionados, recuperados e analisados na íntegra 20 artigos, remanescentes após rigorosa seleção inicial, guiada pelo uso de unitermos e pela aplicação dos critérios de inclusão e de exclusão. Esses artigos, após merecerem análise criteriosa, foram categorizados por temas principais, compondo o corpus da revisão. Essa categorização favoreceu a reflexão crítica sobre 
as dimensões cruciais que caracterizam o estado da arte acerca da temática.

As bases nas quais foi identificado o maior número de artigos foram: SciELO e PePSIC, com seis e cinco artigos, respectivamente, seguidas por EBSCO, com quatro artigos, Oxford, com dois artigos, e LILACS, Wilson e Ovid com um artigo cada. Dos artigos encontrados e recuperados, 11 são de autores nacionais, sendo um publicado em inglês; cinco têm origem nos Estados Unidos, dois na Inglaterra, um na Jamaica e um na China. Apenas dois artigos foram publicados antes de 2005 e em 2013 quatro publicações foram encontradas. Não houve repetição de autoria entre os artigos revisados.

\section{Tabela 1}

Distribuição dos Artigos Recuperados Segundo a Base Indexadora, Ano de Publicação, Autores e País de Origem $(\mathbf{N}=\mathbf{2 0})$

\begin{tabular}{cccc}
\hline Base indexadora & Publicação & País de origem & Autores \\
\hline SciELO & 2004 & Brasil & Arán \& Corrêa \\
SciELO & 2006 & Brasil & Ramos \& Carrara \\
SciELO & 2009 & Brasil & Nucci \& Russo \\
SciELO & 2008 & Brasil & Furlani \\
SciELO & 2013 & Brasil & Miskolci \\
SciELO & 2013 & Brasil & Zago \\
LILACS & 2011 & Brasil & Ferrari \& Andrade \\
PePSIC & 2007 & Brasil & Guedes \& Monteiro-Leitner \\
PePSIC & 2007 & Brasil & Santiago \\
PePSIC & 2009 & EUA & Corbett \\
PePSIC & 2010 & Brasil & Mosmann et al. \\
PePSIC & 2013 & Brasil & Rios \\
Wilson & 2009 & EUA & Hatzenbuehler \\
Ovid & 2011 & EUA & Calzo, Antonucci, Mays, \& Cochran \\
EBSCO & 2011 & Inglaterra & Tebble \\
EBSCO & 2011 & Jamaica & Cowell \& Saunders \\
EBSCO & 2012 & EUA & Bauermeister \\
EBSCO & 2013 & China & Yu, Xiao, \& Liu \\
Oxford & 2004 & EUA & Yarhouse \\
Oxford & 2010 & Inglaterra & Stanivukovic \\
\hline
\end{tabular}

No que tange aos marcos teóricos privilegiados pelos estudos revisados, predominaram referenciais relacionados à Psicanálise, Antropologia e Direito. Com relação ao tipo de estudo, dos 20 artigos recuperados, nove eram de natureza teórica e discutiam questões referentes aos principais agentes responsáveis pelas fronteiras e hierarquias existentes entre as práticas sexu- ais, incluindo a publicidade, além das práticas sustentadas por meio das políticas públicas para enfrentar a violência que assombra os segmentos mais vulneráveis (Arán \& Corrêa, 2004; Ramos \& Carrara, 2006; Tebble, 2011), influências culturais no que tange à orientação sexual, a questão da homoparentalidade (Ferrari \& Andrade, 2011; Stanivukovic, 2010; Yarhouse, 2004) e 
da saúde mental, ressaltando-se a angústia do mal-viver devido às distinções incontornáveis estabelecidas entre o que é "masculino" e o que é "feminino" (Corbett, 2009; Hatzenbuehler, 2009; Santiago, 2007).

Sete estudos empíricos focalizaram questões como a expansão da visibilização da homossexualidade na contemporaneidade, além da forma como os casais homossexuais lidam com suas relações amorosas, comparando-as aos casais heterossexuais (Calzo et al., 2011; Mosmann et al., 2010). Dois estudos eram derivados de pesquisa documental, nos quais, por meio de análise de produtos da publicidade, pode-se conhecer questões acerca da homossexualidade, sendo um deles referente à educação sexual para crianças (Cowell \& Saunders, 2011; Furlani, 2008). Além destes, um estudo de caso buscou conhecer as vivências das relações amorosas entre pessoas do mesmo gênero (Guedes \& Monteiro-Leitner, 2007); e, por fim, uma revisão de literatura se propôs a discutir as teorias referentes à homossexualidade, questionando seu estatuto e se essa categoria pode ou não ser considerada um "terceiro sexo" (Nucci \& Russo, 2009).

Os objetivos dos estudos revisados foram variados, apresentando, em suma, duas tendências principais. A primeira se refere à compreensão das relações entre pessoas do mesmo sexo, no que tange à relação de casal, além das influências sociais que a permeiam, e a segunda tem foco nas lutas da população LGBT em busca da proteção de seus direitos como cidadãos e cidadãs. Esses objetivos não são óbvios e isentos de pressupostos acerca do que é gênero e do que é direito ou não a ser assegurado ao casal formado por pessoas do mesmo sexo. Florescem, assim, discussões acerca de relacionamentos saudáveis nesses casais, levando em consideração não somente os sentimentos de ambos(as) os cônjuges, mas também as influências da sociedade a partir do modelo tradicional composto pela união de um homem e uma mulher e de uma possível construção familiar que só seria legitimada por este arranjo conjugal. A ilegitimidade a que estão relegados os relacionamentos não heterossexuais fomenta a discussão sobre a desconsidera- ção da conjugalidade de transgêneros ou mesmo de especificidades de relacionamentos entre dois homens ou duas mulheres e das inúmeras posições e identidades LGBT. Os objetivos e resultados dos estudos revisados estão sumarizados na Tabela 2.

Para análise crítica das contribuições encontradas, os estudos revisados foram agrupados em três núcleos temáticos, que serão apresentados e discutidos a seguir.

\section{Questões Culturais Relacionadas à Homossexualidade}

Nota-se, a partir da análise dos artigos selecionados, que os relacionamentos amorosos entre pessoas com orientação homossexual vêm ganhando espaço crescente na sociedade, por meio da mídia e também pelas artes, especialmente o cinema e a literatura. Nesse sentido, Stanivukovic (2010) explora a obra de Shakespeare, estimulando polêmicas a fim de construir redescrições acerca do homoerotismo com base nos poemas e peças produzidas durante os séculos XIX e XX. Ainda com o mesmo objetivo, no século XXI, de acordo com Furlani (2008), as diferenças de orientação sexual podem começar a ser entendidas durante a formação escolar, por meio de livros e outros materiais paradidáticos de Educação Sexual, que visam a desconstruir lógicas significativas anteriormente empregadas, uma vez que a descoberta da homossexualidade ocorre geralmente na adolescência, deflagrando confusão nos jovens que interrogam essa condição e exploram novas expressões de seu desejo em experiências sexuais intensificadas nesse período de transição (Calzo et al., 2011). Diante das novas experiências sexuais, que se pulverizam na contemporaneidade, Bauermeister (2012) e Rios (2013) discutem as práticas sexuais e a prevenção do HIV que são feitas por meio de palestras, eventos e uso da mídia em geral, a fim de propagar orientações prescritivas aos jovens. Os autores relatam que a vivência do amor romântico diminui a possibilidade do sexo desprotegido e/ou com vários parceiros. 
Tabela 2

Distribuição dos Artigos Recuperados, Destacando-se Autores, Objetivos, Tipo de Estudo, Principais Resultados e Conclusões Obtidas $(\mathbf{N}=\mathbf{2 0})$ Tipo de estudo

\begin{tabular}{|c|c|}
\hline Autores & Objetivos \\
\hline $\begin{array}{l}\text { Arán \& } \\
\text { Corrêa } \\
\text { (2004) }\end{array}$ & $\begin{array}{l}\text { Analisar os } \\
\text { principais } \\
\text { dispositivos de } \\
\text { discurso que } \\
\text { estabelecem } \\
\text { fronteiras e } \\
\text { hierarquias entre } \\
\text { práticas sexuais. }\end{array}$ \\
\hline $\begin{array}{l}\text { Bauer- } \\
\text { meister } \\
(2012)\end{array}$ & $\begin{array}{l}\text { Examinar a } \\
\text { relação entre o } \\
\text { amor romântico, a } \\
\text { prevenção do HIV } \\
\text { e o uso da Internet } \\
\text { para conhecer } \\
\text { outros homens. }\end{array}$ \\
\hline
\end{tabular}

Calzo et al. Analisar dados

(2011) retrospectivos sobre o calendário das etapas de orientação sexual em uma amostra de

Teórico

A tríade heterossexualidadecasamento-filiação permanece legitimada como a única referência possível para pensar a cultura ou a sociedade.

Empírico Programas de prevenção do HIV podem ser benéficos ao público gay e heterossexual, a fim de promover a conscientização do uso do preservativo, principalmente em relações breves. A Internet facilita o encontro entre pessoas, o que colabora para que romances aconteçam, bem como relações breves que podem trazer consequências nocivas à saúde (como o HIV).

Empírico Identificaram-se três trajetórias de desenvolvimento: precoce, média e tardia. Quase todos os padrões de desenvolvimento foram de identidade centrada. minorias sexuais.

Corbett (2009)

Discutir por que os psicanalistas têm tentado (des)locar os homossexuais em uma teoria de gênero que repousa sobre distinções feminino/ masculino.

Cowell \& Analisar

Saunders informações

(2011) publicamente disponíveis para explorar a postura política pública fundamental em relação aos homossexuais e a homossexualidade.
Teórico

Ainda que tanto os homens heterossexuais quanto os homossexuais prontamente se identifiquem como homens, a identidade de gênero do homem gay se distingue por sua experiência de passividade em relação a outro homem.

Pesquisa documental

São articuladas as implicações observáveis dos resultados das políticas públicas para a sociedade $\mathrm{e}$ os direitos dos homossexuais.
Independentemente do fato de o casamento entre homossexuais se institucionalizar ou não, a visibilidade e o aprofundamento do debate podem ser uma oportunidade para se começar a pensar em novas formas de laços sociais.

Conclui-se que a vivência do amor romântico diminui os riscos dos jovens se envolverem em relações sexuais desprotegidas.
O desenvolvimento precoce é comum, independentemente da faixa etária. As diferenças de gênero observadas no início e o ritmo de desenvolvimento da orientação sexual de identidade demandam pesquisas futuras.

$\mathrm{O}$ tratamento de qualquer homem gay centra-se no reconhecimento de sua experiência inicial de gênero e de como essa experiência se entretece na trama da sua sexualidade.

Evidencia-se um sistema de valor recortado heteronormativamente, refletindo um consenso sobre ambos os lados da divisão política, aplaudido por culturas e opiniões populares. 


$\begin{array}{ll}\text { Ferrari \& } & \text { Abordar } \\ \text { Andrade } & \text { importantes } \\ \text { (2011) } & \text { reivindicações } \\ & \text { feitas por } \\ & \text { homossexuais na } \\ & \text { hipomodernidade: } \\ & \text { casar, adotar e } \\ & \text { procriar. }\end{array}$

Furlani

(2008)

Problematizar
processos de
produção das
diferenças
sexuais a partir de
coleções de livros
paradidáticos
relativos à
Educação Sexual.

\section{Guedes \&}

Monteiro-

Leitner

(2007)

Hatzen-

buehler

(2009)

Miskolci
Explorar como
os gays articulam
plataformas de
busca de parceiros
com o objetivo de
criar relações em
segredo.

Teórico As práticas homossexuais são

discutidas como modos de

funcionamento que questionam as

ficções existentes no Outro, exigindo

novas ficções jurídicas para ordenálas.

Pesquisa Independentemente do nível de docu- ensino, a discussão da sexualidade

mental não deve se privar de mostrar o quanto a vida humana é normatizada, significada e hierarquizada.

Estudo de Os resultados indicaram que os caso modelos de apego aos pais parecem ter influenciado as representações de apego e experiências amorosas dos filhos, mediando seus níveis de depressão.

Teórico

O quadro teórico esboçado postula que as minorias sexuais enfrentam o aumento da exposição ao estresse resultante do estigma.

Empírico O estudo focaliza duas categorias que circulam pelo ciberespaço: os Machos e Brothers. A maioria deles busca o reconhecimento que a sociedade brasileira atribui apenas àquele frequentemente descrito como "homem de verdade", que encarna o modelo de masculinidade que é também sinônimo de heterossexualidade. Marcados pela heteronormatividade e mais conscientes de suas injustiças, esses sujeitos tendem a sabotar as relações com outros homens quanto mais elas apontam para alguma forma de comprometimento.
Aborda-se a clínica da tolerância. Nela, a prudência sem ingenuidade, recomenda um tempo necessário para que se possa dizer algo dos efeitos desse novo estilo de vida em prol do qual os homossexuais lutam.

Questionar as muitas formas de preconceito e de exclusão social é papel de uma Escola que quer e que constrói uma sociedade menos sexista, menos racista, menos misógina e menos homofóbica - e isso começa na Educação Infantil.

Constatou-se que tanto os modelos comportamentais de apego com os pais pareceram repetir-se com os parceiros amorosos na vida adulta, quanto os níveis de segurança e de ativação das relações amorosas pareceram estimar o nível de depressão dos clientes em sentido inverso.

Esse quadro pode, teoricamente, iluminar como o estigma afeta negativamente a saúde mental e informar intervenções clínicas.

Conclui-se que, mesmo às custas de eventuais sofrimentos e frustrações, os Machos e Brothers se afastam do ex-amante, priorizando a vida heterossexual que lhes acena, apesar de tudo, com a desejada aceitação social e familiar. 


$\begin{array}{ll}\text { Mosmann } & \text { Entender como } \\ \text { et al. } & \text { casais de gays e } \\ \text { (2010) } & \text { lésbicas lidam } \\ & \text { com suas relações } \\ & \text { amorosas, } \\ & \text { especificamente } \\ \text { em comparação } & \text { aos casais } \\ & \text { heterossexuais. }\end{array}$

Nucci \& Analisar se e como

Russo

(2009)

$\begin{array}{ll}\text { Ramos \& } & \text { Analisar os } \\ \text { Carrara } & \text { principais aspectos } \\ \text { (2006) } & \text { das agendas } \\ & \text { do movimento } \\ & \text { homossexual, isto } \\ & \text { é, de seus discursos } \\ & \text { e práticas voltadas } \\ & \text { para influir nas } \\ & \text { políticas públicas } \\ & \text { para enfrentamento } \\ \text { da violência. }\end{array}$

Rios

$\begin{array}{ll}\text { Empírico } & \text { As médias de coesão e adaptabilidade } \\ \text { dos homossexuais foram } \\ \text { significativamente maiores quando } \\ \text { comparados às dos heterossexuais, } \\ \text { mas não houve diferença significativa } \\ \text { quanto à comparação entre gays e } \\ \text { lésbicas. }\end{array}$

Revisão As duas formulações teóricas de analisadas apontam para uma literatura naturalização da orientação sexual. Em ambos os casos, trata-se de afirmar que alguém nasce (e não se torna) homossexual.

Teórico

Será necessário, nos próximos anos, um esforço ainda maior de incorporação das organizações de travestis e transexuais dentro do movimento LGBT, na medida em que esses grupos são submetidos às experiências mais críticas de violência; portanto, devem exercer papel decisivo na elaboração de demandas de políticas e na participação direta em práticas de prevenção.

Empírico A análise apontou para processos opressivos relacionados com gênero, idade e amor romântico. Apesar da aceitação tácita das homossexualidades pela cultura religiosa, gênero e idade orientam e oferecem significados para as parcerias sexuais, que tendem a desprestigiar as posições assumidas por homens efeminados e/ou mais jovens.
Fatores como filhos e casamento podem contribuir para depreciar os níveis de qualidade conjugal. A maior flexibilidade dos papéis de gênero e o afeto como fundação da relação conjugal também podem estar associados aos maiores níveis de coesão e adaptabilidade dos casais do mesmo sexo.

Os artigos analisados estão calcados em uma visão da heterossexualidade como característica distintiva de gênero, que aproxima, de um lado, o homem homossexual às mulheres heterossexuais e, do outro, as mulheres homossexuais aos homens heterossexuais.

Um dos dilemas atuais pode ser resumido em: exigir respeito, mas não perder a irreverência LGBT e a afirmação da sexualidade desviante do padrão heteronormativo; demandar a criminalização da homofobia, mas não a regulação da diversidade sexual.

Seja nas parcerias fixas, seja nas ocasionais, os elementos sociais atuam, podendo fazer emergir arranjos sexuais contextuais que tornem os jovens com práticas homossexuais mais vulneráveis ao HIV e à Aids.

o que os torna

socialmente mais suscetíveis à epidemia de Aids. 


$\begin{array}{ll}\text { Santiago } & \text { Mostrar em que } \\ \text { medida a questão } & \text { homossexual } \\ & \text { introduz } \\ & \text { questionamentos } \\ & \text { importantes sobre } \\ & \text { a angústia de mal- } \\ & \text { viver entre os sexos } \\ & \text { nas sociedades } \\ & \text { estruturadas pela } \\ & \text { via democrática do } \\ & \text { individualismo de } \\ & \text { massa. }\end{array}$

Stanivu-

(2010)

Tebble

(2011)

Discutir as
construções
intelectuais e
culturais da
homossexualidade
no século XIX, a
partir da obra de
Skakespeare.

Examinar a

relação entre homossexualidade e o conceito de publicidade.

Yarhouse

Apresentar uma

(2004)

interpretação

alternativa, de cunho metafísico, sobre a orientação sexual e identidade sexual.

Yu et al.

Compreender

a violência no namoro entre casais homossexuais na China.

\section{Zago}

Teórico

$$
\begin{aligned}
& \text { Comprova-se que as ciências } \\
& \text { alemã e inglesa, que tratam da } \\
& \text { homossexualidade do século XX, } \\
& \text { têm em comum com a ciência do } \\
& \text { desenvolvimento da psicologia da } \\
& \text { sexualidade e da psicanálise do } \\
& \text { século XIX, características que } \\
& \text { definem a homossexualidade, além de } \\
& \text { foco no caráter e na interioridade. }
\end{aligned}
$$

Teórico assiste-se a um novo modo de homossexualidade. Tal concepção subverte o posicionamento freudiano e também a formulação da questão paterna sob o prisma da sua capacidade de proceder a articulação entre o desejo e a Lei.

Teórico

Teórico

Empírico

Entre aqueles que viveram abuso, $83,9 \%$ dos homens gays nunca contaram a ninguém sobre $o$ acontecido. A experiência de alguma forma de abuso por homens gays foi 5,07 vezes maior do que a taxa de abuso entre homens heterossexuais.

Elementos da biossociabilidade gay on-line apontam para a disputa de inteligibilidade que se dá em um âmbito que resgata o princípio geral do dispositivo de sexualidade, que é formar corpos adequadamente sexuados de acordo com a norma heterossexual.

Refletir os
conceitos de
biossociabilidade,
armário e
sexualidade
como forma de
analisar os usos
que vêm sendo
feitos de sites de
relacionamento
gay.

As novas formulações conceituais refletem a necessidade de a psicanálise estar à altura da atualidade clínica da homossexualidade masculina.

$\mathrm{O}$ autor identifica

ideias críticas sobre

a homossexualidade em Shakespeare, especialmente nos sonetos, e as relaciona às figuras principais que discutiram a homossexualidade em seus escritos.

Afirma-se que a teoria política do tabu apresenta uma nova política, estabelecendo um novo padrão de justiça.

Os médicos devem fornecer aos clientes consentimento informado para facilitar o desenvolvimento de sua identidade sexual.

Em geral, violência no namoro é mais prevalente em homens homossexuais do que nos heterossexuais. Esforços devem ser feitos para prevenir a violência no namoro, especialmente entre os homens gays, na China.

Com seus modos emblemáticos de superexposição dos corpos, a biossociabilidade entre homens gays nos sites de relacionamento não prescinde da atuação insidiosa do dispositivo de sexualidade, pelo contrário, remetem-se um ao outro, produzindo outras visibilidades, invisibilidades e subjetividades. 
De acordo com Ferrari e Andrade (2011) e Furlani (2008), na contemporaneidade as políticas referentes à identidade sexual são de suma importância para que se instaure uma nova visão acerca do relacionamento afetivo-sexual, ressaltando a importância da adoção de práticas de sexo seguro, do reconhecimento da população LGBT e de seus direitos elementares de viver uma vida com dignidade, dos que vivenciam o autoerotismo, além das várias outras maneiras de se viver a sexualidade, incluindo o direito de casar, procriar e adotar. Nesse sentido, ressalta-se que a parentalidade não significa, necessariamente, estabelecer um laço de parentesco, como é assumido na família adotiva. Logo, casais do mesmo sexo podem ser investidos de papéis e funções a serem assumidas em relação ao outro, como, por exemplo, proteger, alimentar, educar, entre outros e, acima de tudo, amar. Essas são funções que podem ser exercidas por qualquer pessoa, o que prova que casais do mesmo sexo têm condições para adotar ou educar filhos oriundos de relacionamentos anteriores, do mesmo modo como casais héteros (Ferrari \& Andrade, 2011).

As questões relacionadas à constituição familiar, em destaque para o casamento, são assumidas como referências pelos homossexuais, por exemplo, que buscam o direito de se casar, formalizando suas uniões estáveis, o que os distingue dos heterossexuais, que estão cada vez mais recorrendo ao divórcio e optam por relações consensuais não formalizadas ou institucionalizadas (Ferrari \& Andrade, 2011). Em contrapartida, ainda há homossexuais que buscam ajuda terapêutica para tentarem sentir menos atração por pessoas do mesmo sexo e maior capacitação heterossexual. Cabe ao profissional ajudar o cliente a reconhecer sua identidade e auxiliá-lo(a) a lidar com ela (Yarhouse, 2004).

Para Calzo et al. (2011), o foco no desenvolvimento da identidade sexual pode colaborar para que se reduza a violência contra a população LGBT. Ainda nesse sentido, Ferrari e Andrade (2011) discutem também os direitos que casais do mesmo sexo reivindicam em termos de valores e recursos institucionais, embora, contemporaneamente, sejam exploradas ques- tões individualistas e ligadas à intimidade do casal. Os autores levantam uma discussão acerca do direito não apenas de se casar, de oficializar a união, mas também de adotar e procriar, direitos secularmente assegurados à população heterossexual.

Yarhouse (2004) acredita que a linguagem utilizada em intervenções terapêuticas influencia a maneira como a população LGBT percebe sua orientação sexual. Esta, se não for considerada "apropriada", pode gerar mais conflitos internos. De acordo com pesquisa realizada por Calzo et al. (2011), crê-se que a orientação afetivo-sexual se desenvolve precocemente, o que é confirmado por jovens e pessoas mais velhas. Desse modo, os psicoterapeutas devem estar atentos ao modo como se dão os recentes arranjos amorosos na contemporaneidade, a fim de que se possa estabelecer uma relação de ajuda contextualizada e com foco nas demandas de cada sujeito. Não se trata, porém, de promover intervenções específicas com a população LGBT, haja vista que os momentos de crise e de identificação com uma posição homoafetiva não são exclusivos dessas pessoas.

\section{Relações Amorosas entre Pessoas do Mesmo Sexo: O Amor tem Muitas Faces}

Para Guedes e Monteiro-Leitner (2007), os fatores ambientais e de contexto têm considerável influência nas relações interpessoais, em especial em um caso mencionado, em que sujeitos não apresentavam sinais de estressores antes do término de uma relação e, após a separação, a depressão foi uma das consequências da perda. Sendo assim, considera-se que pode haver relação entre a depressão e o modelo de apego experienciado, o que mostrou que muitas das experiências vividas com os pais refletem-se na relação amorosa com parceiros, como corroborado por Forrest (2010). Santiago (2007), a partir do referencial psicanalítico, destaca que nos últimos tempos tem sido considerado anacrônico não ver a homossexualidade como um estilo de vida, entendendo-se que caberia a cada indivíduo fazer sua escolha em termos da orientação sexual. Contudo, é amplamente aceito que orientação 
sexual não é uma escolha, ou muito menos uma opção consciente, uma vez que ela se impõe ao indivíduo.

A boa notícia é que, a partir dos novos discursos psiquiátricos, homossexuais não comporiam mais uma "categoria de perversão". Em contrapartida, para Nucci e Russo (2009), a homossexualidade ainda é vista por meio de dois prismas: a primeira opinião é dada pelos próprios homossexuais, que afirmam não terem se tornado homossexuais, mas sim terem nascido assim; logo, lutam para terem direitos sexuais e reprodutivos iguais aos heterossexuais, reforçando o estereótipo binário e não abrindo a possibilidade de uma leitura mais plural e generosa acerca das relações de gênero e identidade. A segunda visão é mantida pelos opositores da homossexualidade, geralmente filiados a algum credo religioso; estes, como aqueles que acreditam que a homossexualidade (ou quaisquer comportamentos sexuais da população LGBT) é aprendida ou escolhida, pensam que ela pode ser mudada ou, até mesmo, curada e erradicada por meio de técnicas de docilização dos corpos.

Por meio de estudos de casos, percebe-se a importância da psicoterapia e do papel desempenhado pelo terapeuta no atendimento à população LGBT. A psicoterapia pode proporcionar diversas mudanças emocionais, contribuindo para mitigar sintomas de ansiedade e depressão (Guedes \& Monteiro-Leitner, 2007; Santiago, 2007). A partir do momento em que as melhoras são notáveis, acredita-se que houve um bom relacionamento entre analista e analisando, sendo possível modificar quadros de sofrimento psíquico, progredindo no que tange à compreensão das relações afetivo-amorosas (Guedes \& Monteiro-Leitner, 2007). Santiago (2007) acredita na melhora nas situações em que os analistas trabalham de acordo com as necessidades apresentadas, principalmente nos casos em que é o próprio sujeito quem procura espontaneamente o tratamento. As queixas são diversas e cabe valorizar as vivências do(a) paciente, a fim de que se obtenha êxito no processo terapêutico (Santiago, 2007).

Na visão de Corbett (2009), a homossexualidade involucra uma ameaça ao que já se tem estabelecido como certeza no que se refere às relações tradicionais de gênero masculino/feminino. A psicanálise, mais uma vez, entra em cena não apenas para contribuir com a compreensão da homossexualidade, mas para questionar o modo como a orientação sexual tem se destacado como categoria identitária na contemporaneidade. Ao dizer que é possível transformar os homossexuais masculinos em "mulheres falsificadas", obscurecem-se as vicissitudes de gênero no lugar de abordar o modo pelo qual a afetividade entre pessoas do mesmo sexo desafia a dualidade convencional masculino-feminino. Corbett (2009) ressalta o que Nucci e Russo (2009) afirmam, sustentando que a relação homem/ mulher, no pensamento judaico-cristão, tem por objetivo precípuo a reprodução, diferentemente da relação homossexual, na qual essas funções tipicamente estão dissociadas, evidenciando o caráter arbitrário da associação sustentada por certas crenças religiosas.

Além da psicanálise referida por Corbett (2009), outras teorias e abordagens concorrem para explicar as origens da homossexualidade, dentre elas, a teoria do "terceiro sexo". Tal teoria remete ao pensamento de que o corpo masculino era tomado por uma alma feminina. Há também as teorias calcadas no modelo biológico, que enfatizam a exposição a hormônios pré-natais, além de outras, consideradas vagas, como a metafísica, que envolve noções de alma e mente, e também as mais concretas, que levam em consideração o cérebro e o funcionamento neuropsicológico (Nucci \& Russo, 2009).

A falta de um consenso teórico em torno da compreensão da homossexualidade e a representação de passividade masculina podem gerar certo repúdio e estigmatização (Corbett, 2009). Seguindo esse pensamento, Hatzenbuehler (2009) estudou as psicopatologias vividas pelas mulheres homossexuais, às quais refere como "minorias sexuais". De acordo com o autor, pesquisas comprovam que a exposição ao estresse, associado ao estigma e às consequências psicológicas da determinação nas relações diárias, aumenta o risco para o desenvolvimento de psicopatologias. A argumentação de Hatzenbuehler é corroborada por Corbett (2009), ao relatar o caso 
de um paciente que diz se sentir fora do normal quando se compara a outro homem, heterossexual; o rapaz não consegue descrever o que sente em relação à sua orientação sexual, dizendo que parece que a sociedade roubou dele as palavras que poderiam explicar seus sentimentos. Corbett conclui que é incumbência dos cientistas desenvolverem uma teoria que respeite a diversidade $\mathrm{e}$ seu papel no desenvolvimento humano, mais do que o desejo de criar uma metafísica de gênero falsamente simétrica.

\section{Questões Culturais e Históricas Relacionadas à Homossexualidade}

Para Arán e Corrêa (2004), a homossexualidade causa impacto na sociedade, que ainda defende a tríade que une heterossexualidade, casamento e filiação, sendo os novos laços homoafetivos uma ameaça concreta aos limites e normas sociais e de gênero vigentes. Já na visão de Mosmann et al. (2010), ainda não há respostas para as perguntas referentes ao futuro das relações homossexuais, como, por exemplo, se eles conseguirão fazer valer seus papéis parentais, assim como os heterossexuais o fazem, respondendo, desse modo, às expectativas sociais, e se essas vivências irão reforçar ou prejudicar as relações afetivas dos casais.

É possível perceber as diferenças entre as culturas no que se refere à abordagem da homossexualidade. Na Jamaica é possível observar a cultura enraizada na heteronormatividade, ou seja, orientações sexuais diferentes da heterossexual são marginalizadas, ignoradas ou perseguidas por práticas sociais, crenças ou políticas (Guimarães, 2009), sendo reconhecido internacionalmente por ser um dos países mais homofóbicos e no qual os movimentos LGBT não têm voz e são perseguidos (Cowell \& Saunders, 2011). Também na China os casos de homofobia e abuso são frequentes. Por meio da pesquisa acerca da violência nos namoros entre homossexuais, de $\mathrm{Yu}$ et al. (2013), nota-se que mais de $80 \%$ dos 418 entrevistados sofreram algum tipo de abuso advindos dos próprios parceiros e tiveram que manter segredo sobre o fato. Enquanto isso, no Brasil, os movimentos LGBT atualmente pautam a militância pelo empenho em cessar a violência cada vez mais crescente contra essa população, utilizando-se dos poderes públicos e participando ativamente de práticas preventivas (Ramos \& Carrara, 2006).

A legitimação desses direitos tem início no contexto dos poderes Legislativo e Judiciário, tendo como meta diminuir a discriminação, a intolerância e a homofobia, e ampliar os direitos dos homossexuais, como, por exemplo, permitindo que estes possam regularizar a relação amorosa por meio da união civil entre pessoas do mesmo sexo. Outro aspecto de suma importância para a visibilidade da luta pelos direitos dos homossexuais ocorreu nos anos 1990, quando foram abertos nichos de mercado voltados ao público gay. Vale ressaltar que, nessa mesma época, assuntos voltados à parentalidade, mais especificamente à adoção, compuseram tal cenário, além do início das Paradas do Orgulho Gay. Outro fator determinante para a compreensão contextualizada dos assuntos relacionados à homossexualidade e ao homoerotismo são os trabalhos de pesquisa e outras iniciativas acadêmicas, que oferecem base científica para as discussões, impulsionando o surgimento de novas perspectivas (Mosmann et al., 2010; Ramos \& Carrara, 2006; Vecho \& Schneider, 2005). É importante lembrar que, de acordo com a literatura, existem tanto fatores de risco como de proteção em relação à qualidade e estabilidade nas uniões amorosas.

Nessa discussão, deve-se destacar a publicidade, haja vista que é por meio dela que se dão os primeiros passos em busca dos direitos perante a sociedade, apesar de a homossexualidade ser ainda um assunto complexo a ser tratado, devido à sua dimensão pública e privada. A publicidade pode ser uma aliada no combate à desigualdade, ressaltando o direito que os homossexuais têm de exigir respeito sem deixar de ser o que são e de fazer o que fazem, como ocorre nas Paradas do Orgulho LGBT, visando, acima de tudo, ao combate da homofobia (Ramos \& Carrara, 2006; Tebble, 2011). Miskolci (2013) e Zago (2013) também enfatizam o papel da mídia, especialmente a Internet, como fonte que tem contribuído de forma significativa não somente para que haja esclarecimentos acerca da homossexualida- 
de, como também têm contribuído para que gays conheçam e reconheçam outros gays, surgindo novas formas de relações de cunho amoroso, laços de amizades e sociabilidade em torno de grupos criados para discutirem questões relacionadas às suas vivências e novas descobertas.

Um dos entraves para se reduzir a intolerância à homossexualidade surge a partir do momento em que se se começam a desestabilizar os pressupostos sociais e políticos vigentes, por exemplo, quando se cogita a possibilidade de legalizar o casamento entre homossexuais, uma vez que sua materialização mudaria o ideário teórico-cultural tido como referência normativa. De acordo com as pesquisas, no que tange à coesão e adaptabilidade, os casais homossexuais apresentam maiores escores nesses fatores, expressando maior nível de qualidade conjugal em comparação aos casais heterossexuais. Isso levanta questionamentos, dentre eles, se casais de pessoas do mesmo sexo seriam inclusive mais felizes do que casais de sexo diferente. De acordo com o discurso psicanalítico, a constituição do casal homossexual representa, no plano inconsciente, ameaça à propagação da espécie, o que fica implícito, conquanto não haja ameaças concretas de que esses casais prejudicariam a saúde psíquica ou os direitos das crianças (Arán \& Corrêa, 2004; Mosmann et al., 2010).

\section{Considerações Finais}

A revisão de literatura permitiu compreender como os relacionamentos amorosos entre pessoas do mesmo sexo vêm sendo investigados na literatura científica. Pelos achados encontrados, fica clara a necessidade de elaboração de investigações que busquem colher informações junto aos próprios homossexuais, avançando em relação à tendência dominante de circunscreverem-se a estudos teóricos em torno da homossexualidade como categoria de análise. Mais do que buscar compreender o que é a homossexualidade e como ela pode se manifestar no plano das relações afetivas, há que se reconhecê-las em sua concretude e pluralidade, a partir do cotidiano de quem as vivencia e dos seus desejos e formas peculiares de vinculação. Ao comparar os arranjos homossexuais aos heterossexuais, corre-se o risco de traçar paralelos discriminatórios. Assim, investigar os relacionamentos amorosos entre pessoas do mesmo sexo não deveria visar à comparação com o modelo heterossexual, mas sim ter em vista conhecê-los em suas especificidades e singularidades, como formas genuínas de expressão da afetividade.

Com a crescente discussão acerca dos direitos da população LGBT no Brasil e em diversas partes do mundo, as pessoas com orientação homossexual vêm ganhando mais espaço e visibilidade, embora ainda perdure a discriminação, intolerância e violência violência contra essa população. Tanto no Brasil como no exterior podem-se observar os avanços referentes a maior participação e reconhecimento das pessoas que mantêm relacionamentos amorosos com pessoas do mesmo sexo, convivendo ainda com a forte presença da desigualdade entre homossexuais e heterossexuais. Em alguns países, como na Jamaica e Uganda, a homossexualidade é absolutamente discriminada, chegando a ser criminalizada. Em outros países, como o Brasil, a intolerância também deixa suas marcas indeléveis, e a homofobia é entronizada na vida social. Estudos destacam o preconceito atávico ainda vigente, acirrando o sentimento de desigualdade perante os heterossexuais (Arán \& Corrêa, 2004; Corbett, 2009; Cowell \& Saunders, 2011; Hatzenbuehler, 2009; Prado \& Machado, 2008). A despeito dos recentes progressos, o ranço homofóbico ainda persiste, fomentando a violência e obstruindo os ganhos sociais, no que tange ao reconhecimento dos homossexuais como cidadãos plenos de direitos.

A comprovação de que a coesão e adaptabilidade entre casais gays e lésbicos é maior em comparação aos casais heterossexuais (Mosmann et al., 2010) é um dos achados que devem ser levados em consideração ao se refletir acerca dos preceitos impostos pela cultura heteronormativa. Vale lembrar, ainda, que nem sempre a cultura apregoou o ideal de exclusividade da heterossexualidade, como pode ser visto em estudos que analisam documentos antigos, quando a homossexualidade masculina era parte integrante dos costumes e da vida social, e até mesmo "fazia 
do homem mais homem" pelo fato de praticar sexo com outro homem (Lomando \& Wagner, 2009; Richlin, 2005; Spencer, 1996). A tolerância a práticas sexuais homoafetivas foi mudando de acordo com os acontecimentos históricos, até ser sumariamente abolida com o advento do cristianismo. A perseguição histórica em relação aos homossexuais acarretou no que, contemporaneamente, designamos como homofobia, conceito que abarca as mais diversas formas de violência para com os homossexuais (Andrade \& Ferrari, 2009).

Os esforços para que a homossexualidade seja respeitada estão cada vez mais presentes nos meios educacionais (Calzo et al., 2011). Intervenções terapêuticas que não visem à normalização das experiências amorosas também podem contribuir para que homossexuais se aceitem, sintam-se mais seguros e possam, efetivamente, posicionar-se na luta pelos seus direitos (Guedes \& Monteiro-Leitner, 2007).

No meio acadêmico, há necessidade cada vez mais premente de desenvolver novos estudos, ampliando os contextos de investigação e as abordagens empregadas, a fim de situar a homossexualidade não como uma categoria fixa ou que deva ser comparada a outras, mas como uma orientação que deve ser igualmente respeitada, investigada e analisada de modo crítico. Na presente revisão destaca-se a necessidade de contextualizar as discussões em torno da homossexualidade, posicionando os elementos culturais, sociais, históricos e afetivos no sentido de promover leituras cada vez mais flexíveis e que convidem diferentes audiências na compreensão dos relacionamentos amorosos na contemporaneidade.

\section{Referências}

Andrade, M. R. M., \& Ferrari, I. F. (2009). Legitimação do laço homossexual: Um acolhimento possível na realidade social da hipermodernidade. Revista Mal-Estar e Subjetividade, 9(4), 1145-1172.

Arán, M., \& Corrêa, M. V. (2004). Sexualidade e política na cultura contemporânea: O reconhecimento social e jurídico do casal homossexual. Ciência e Saúde Coletiva, 14(2), 329-341.
Badinter, E. (1993). XY: Sobre a identidade masculina. Rio de Janeiro, RJ: Nova Fronteira.

Bauermeister, J. A. (2012). Romantic ideation, partner-seeking, and HIV risck among young gay and bisexual men. Archives of Sexual Behavior, 41(2), 431-440. doi:10.1007/s10508-011-9747-z

Calzo, J. P., Antonucci, J. P., Mays, V. M., \& Cochran, S. D. (2011). Retrospective recall of sexual orientation identity development among gay, lesbian, and bisexual adults. Developmental Psychology, 47(6), 1658-1673. doi:10.1037/ a0025508

Corbett, K. (2009). O mistério da homossexualidade. Jornal de Psicanálise, 42(76), 159-176.

Cowell, N. M., \& Saunders, T. S. (2011). Exploring heteronormativity in the public discourse of Jamaican legislators. Sexuality \& Culture, 15(4), 315-331. doi:10.1007/s12119-011-9105-2

Diehl, H. (2002). Família em cena: Tramas, dramas e transformações. Petrópolis, RJ: Vozes.

Féres-Carneiro, T. (1998). Casamento contemporâneo: O difícil convívio da individualidade com a conjugalidade. Psicologia: Reflexão e Crítica, 11(2), 379-394.

Ferrari, I. F., \& Andrade, M. R. M. (2011). Casar, filiar, procriar: Reivindicações na homossexualidade masculina. Tempo Psicanalítico, 43(1), 25-43.

Forrest, S. (2010). Young men in love: The (re)making of heterosexual masculinities through "serious" relationships. Sexual and Relationship Therapy, 25(2), 206-218. doi:10.1080/14681991 003660260

Furlani, J. (2008). Mulheres só fazem amor com homens? A Educação Sexual e os relacionamentos entre pessoas do mesmo sexo. Pro-Posições, 19(2), 111-131.

Galli, R. A., Vieira, E. M., Giami, A., \& Santos, M. A. (2013). Corpos mutantes, mulheres intrigantes: Transexualidade e cirurgia de redesignação sexual. Psicologia: Teoria e Pesquisa, 29(4), 447457. doi:10.1590/S0102-37722013000400011

Guedes, D. D., \& Monteiro-Leitner, J. (2007). Modelos de apego, homossexualidade masculina e depressão: Um relato de experiência. Estudos de Psicologia (Natal), 12(3), 291-297.

Guimarães, A. F. P. (2009). O desafio histórico de "tornar-se um homem homossexual": Um exercício de construção de identidades. Temas em Psicologia, 17(2), 553-567. 
Hatzenbuehler, M. L. (2009). How does sexual minority stigma "get under the skin"? A psychological mediation framework. Psychological Bulletin, 135(5), 707-730. doi:10.1037/a0016441

Heilborn, M. L. O. (1995). O que faz um casal, casal? Conjugalidade, igualitarismo e identidade sexual em camadas médias urbanas. In I. Ribeiro \& A. C. T. Ribeiro (Eds.), Família em processos contemporâneos? Inovações culturais na sociedade brasileira (pp. 91-128). São Paulo, SP: Loyola.

Instituto Brasileiro de Geografia e Estatística. (2011). Censo contabiliza $60 \mathrm{mil}$ casais gays; metade mora no Sudeste. Recuperado em http://noticias.uol.com.br/ultnot/ multi/?hashId=censocontabiliza-60-mil-casais-gays-metade-mora-no-sudeste-0402CC9C3772 CC911326\&mediaId $=11239793$

Lomando, E., \& Wagner, A. (2009). Reflexões sobre termos e conceitos das relações entre pessoas do mesmo sexo. Revista Sociais e Humanas, 22(2), $1-18$

Miskolci, R. (2013). Machos e Brothers: Uma etnografia sobre o armário em relações homoeróticas masculinas criadas on-line. Revista Estudos Feministas (Florianópolis), 21(1), 301-324. doi:10.1590/S0104-026X2013000100016

Moraes, M. C. J., Moraes, G. R. J., Veloso, F. G. C., Alves, G. M. M., \& Tróccoli, B. T. (2009). Influência das percepções maritais/parentais sobre relacionamentos de conjugalidade: Método ADI/TIP. Psicologia: Teoria e Pesquisa, 25(4), 647-655.

Moscheta, M. S., \& Santos, M. A. (2006). Metáforas da vida a dois: Sentidos do relacionamento conjugal produzidos por um casal homoafetivo. Revista Brasileira de Sexualidade Humana, 17(2), 217-231.

Moscheta, M. S., \& Santos, M. A. (2009). Relação conjugal homoafetiva: Revolução ou acomodação? In M. V. Cunha, S. R. Pasian, \& G. Romanelli (Eds.), Pesquisas em Psicologia: Múltiplas abordagens (pp. 129-152). São Paulo, SP: Vetor.

Mosmann, C. P., Lomando, E., \& Wagner, A. (2010). Coesão e adaptabilidade conjugal em homens e mulheres hetero e homossexuais. Barbarói, 2(33), 135-152.

Nucci, M. F., \& Russo, J. A. (2009). O terceiro sexo revisitado: A homossexualidade no Archives of Sexual Behavior. Physis: Revista de Saúde Coletiva, 19(1), 127-147. doi:10.1590/S010373312009000100007

Pennings, G. (2011). Evaluating the welfare of the child in same-sex families. Human Reproduction, 26(7), 1609-1615. doi:10.1093/humrep/ der 109

Pereira, C., Torres, A. R. R., Pereira, A., \& Falcão, L. (2011). Preconceito contra homossexuais e representações sociais da homossexualidade em seminaristas católicos e evangélicos. Psicologia: Teoria e Pesquisa, 27(1), 73-82.

Perroni, S., \& Costa, M. I. M. (2008). Psicologia clínica e homoparentalidade: Desafios contemporâneos. In Fazendo Gênero 8: Corpo, violência e poder. Florianópolis, SC: Universidade Federal de Santa Catarina.

Prado, M. A. M., \& Machado, F. V. (2008). Preconceito contra homossexualidades: Hierarquia da invisibilidade. São Paulo, SP: Cortez.

Ramos, S., \& Carrara, S. (2006). A constituição da problemática da violência contra homossexuais: A articulação entre ativismo e academia na elaboração de políticas públicas. Physis: Revista de Saúde Coletiva, 16(2), 185-205.

Richlin, A. (2005). Eros underground: Greece and Rome in gay print culture. Journal of Homosexuality, 49(3-4), 421-461. doi:10.1300/ J082v49n03_15

Rios, L. F. (2013). Homossexualidade, juventude e vulnerabilidade ao HIV/Aids no candomblé fluminense. Temas em Psicologia, 21(3), 10511066. doi:10.9788/TP2013.3-EE14PT

Santiago, J. (2007). Atualidade clínica da homossexualidade masculina: Solução ou escolha de objeto. Psicologia em Revista, 13(2), 253-266.

Santos, M. A. (2011). Prostituição masculina e vulnerabilidade às DSTS/aids. Texto \& Contexto Enfermagem, 20(1), 76-84. doi:10.1590/S010407072011000100009

Santos, M. A., Brochado, J. U., Jr., \& Moscheta, M. S. (2007). Grupo de pais de jovens homossexuais. SMAD, Revista Eletrônica de Saúde Mental, Álcool e Drogas, 3(2). Recuperado em http://www. revistasusp.sibi.usp.br/scielo.php?script $=$ sci arttext\&pid=S1806-69762007000200002\&lng= pt\&nrm $=$ iso

Scorsolini-Comin, F. (2014). Guia de orientação para a iniciação científica. São Paulo, SP: Atlas. 
Scorsolini-Comin, F., \& Santos, M. A. (2012). Correlations between subjective well-being, dyadic adjustment and marital satisfaction in Brazilian married people. The Spanish Journal of Psychology, 15(1), 166-176. doi:10.5209/rev SJOP.2012.v15.n1.37304

Simões, J. A., \& Facchini, R. (2009). Na trilha do arco-iris: Do movimento homossexual ao LGBT. São Paulo, SP: Fundação Perseu Abramo.

Souza, E. M., \& Carrieri, A. P. (2010). A analítica queer e seu rompimento com a concepção binária de gênero. RAM - Revista de Administração Mackenzie, 11(3), 46-70.

Spencer, C. (1996). Homossexualidade: Uma história. Rio de Janeiro, RJ: Record.

Stanivukovic, G. (2010). Shakespeare and homosexuality. Forum for Modern Language Studies, 46(2), 138-151. doi:10.1093/fmls/cqq002

Tavares, F. H., Souza, I. A., Ferreira, I. E. V., \& Bomtempo, T. V. (2010). Apontamentos para o reconhecimento das uniões homossexuais face ao paradigma do Estado Democrático de Direito. Revista Direito GV, 6(2), 443-468.

Tebble, A. J. (2011). Homosexuality and publicness: Towards a political theory of the taboo. Political Studies, 59(4), 921-939. doi:10.1111/j.14679248.2011.00884.x

Toledo, L. C. C. (2008). A família no discurso dos membros de familias homoparentais (Tese de doutorado, Instituto de Psicologia, Universidade de São Paulo, SP, Brasil).

Uziel, A. P., Andrade, R., Antonio, C. A., Ferreira, I. T. O., Machado, R. S., Medeiros, L. S. M., ...Tavares, M. (2006). Parentalidade e conjugalidade: Aparições no movimento homossexual. Horizonte Antropológico, 12(26), 203-227.
Vaitsman, J. (1994). Flexíveis e plurais: identidade, casamento e família e circunstâncias pós-modernas. Rio de Janeiro, RJ: Rocco.

Vecho, O., \& Schneider, B. (2005). Homoparentalité et développement de l'enfant: bilan de trent ans de publications. Psychiatrie de l'Enfant, 48(1), 271-328. doi:10.3917/psye.481.0271

Yarhouse, M. A. (2004). Homosexuality, ethics and identity synthesis. Christian Bioethics, 10(3), 239-257.

Yu, Y., Xiao, S., \& Liu, K. Q. (2013). Dating violence among gay men in China. Journal of Interpersonal Violence, 28(12), 2490-2504. doi:10.1177/0886260513479028

Zago, L. F. (2013). "Caça aos homens disponíveis": Corpo, gênero e sexualidade na biossociabilidade gay online. Revista Latino Americana Sexualidade, Saúde e Sociedade, 13(1), 83-98.

Zambrano, E. (2006). Parentalidades “impensáveis": Pais/mães homossexuais, travestis e transexuais. Horizonte Antropológico, 12(26), 123-147.

Recebido: 22/03/2013

$1^{a}$ revisão: $12 / 05 / 2014$

$2^{a}$ revisão: $11 / 06 / 2014$

Aceite final: 26/06/2014 